\title{
Occupational Health
}

National Cancer Institute

\section{Source}

National Cancer Institute. Occupational Health. NCI Thesaurus. Code C17381.

The identification and control of risks and hazards in the workplace to establish and

maintain a safe and healthy work environment. 